\title{
The analysis of vibrations of gasoline and diesel vehicles as a function of their engine sizes
}

This paper presents a study of vibrations appearing in a vehicle in the process of its operation. The authors describe the primary source of the vibrations and their propagation in the entire structure. The observations were performed on the passenger cars with various gasoline and diesel engines. The aim was to examine the level of damping factor in the different locations in the car, precisely specified for the purpose of this studies. The secondary goal was to develop an effective method of obtaining and analyzing signals generated during the engine operation. The chosen instrument was Laser Doppler Vibrometer (LDV), which is used as the non-intrusive measurement utensil to detect velocity variations in designated places. The signals are gathered and collected as group of sinusoidal characteristics in the time domain. In order to achieve specific information about every component of the original signal, the authors apply Fast Fourier Transform (FFT) as the analyzing method. It allows to distinct the basic sinusoidal characteristics in the frequency domain through the spectral analysis. Based on the results, the authors are able to distinguish the dominant modes from the complex signal and indicate their impact on the car.

Key words: vehicle, vibration, engine, Fourier, vibrometer

\section{Introduction}

The non-invasive diagnostic are always the most preferable measurement methods in order to recognize current condition of the examined object, especially when there is no access to multiple, similar items and it is not allowed to damage the integrity of one's parts. Considering these requirements, it is always a challenge to perform valid and detailed measurements. Taking this into account, the certain collection of prerequisites has to be fulfilled:

- understanding the theoretical basics of the measurements,

- proper interpretation of the results,

- consideration of the outside disturbances.

One of the information we can obtain from various objects is mechanical vibration. It is a phenomenon where kinetic energy is converted into potential energy and vice versa until the causing force ceases [1]. The complexity of measurements depends on numbers of degrees of freedom (DOF). In this particular case, the engine as well as the entire car structure has a huge number of the DOF. In order to simplify the calculations, the whole system is represented by deformable constraints, material particles and rigid bodies, depending on the size of the object. The standard approach is to assume the system as continuous, where the number of the DOF is determined. It allows to use integral equations for this calculations, instead of differential ones for discretization [2].

The purpose of this research was to verify the generation of the vibrations and its dependence on the engine size, type of fuel and optional supercharging.

\section{Measurements}

\subsection{Investigated objects}

The tests were performed on the three, new Fiat Bravo Model 198 cars: 54A, 54G and 54W with respectively engines: gasoline 1.4BZ 90CV CD, gasoline supercharged 1.4BZ 120CV CD and diesel supercharged 1.6 105CV CD. The engines were mounted crosswise. Their supports func- tion as a structural connection between drive unit and the car body. Each support has a mount with rubber to minimalize the transmission of the driving vibrations generated by the engine and spread into the entire structure [3].

Table 1. Engines specification [4]

\begin{tabular}{|c|c|c|c|}
\hline & \multicolumn{3}{|c|}{ Engine type } \\
\cline { 2 - 4 } & $\begin{array}{c}1.4 \mathrm{BZ} 90 \mathrm{CV} \\
\mathrm{CD}\end{array}$ & $\begin{array}{c}1.4 \mathrm{BZ} 120 \mathrm{CV} \\
\mathrm{CD}\end{array}$ & $1.6105 \mathrm{CV}$ CD \\
\hline $\begin{array}{c}\text { Engine } \\
\text { capacity } \\
\text { [cm3] }\end{array}$ & 1368 & 1368 & 1598 \\
\hline Power [HP] & 90 & 120 & 105 \\
\hline $\begin{array}{c}\text { Engine } \\
\text { mounting }\end{array}$ & Front crosswise & Front crosswise & Front crosswise \\
\hline $\begin{array}{c}\text { Number of } \\
\text { cylinders }\end{array}$ & 4 & 4 & 4 \\
\hline $\begin{array}{c}\text { Number of } \\
\text { valves per } \\
\text { cylinder }\end{array}$ & 4 & 4 & 4 \\
\hline $\begin{array}{c}\text { Type of } \\
\text { camshaft }\end{array}$ & OHC & OHC & DOHC \\
\hline
\end{tabular}

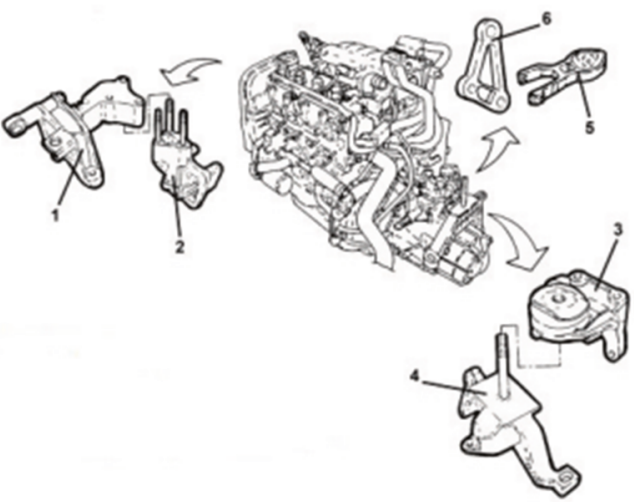

Fig. 1. Elements for mounting examined object ( 1 - flexible connector on timing gear side, 2 - rigid support on timing gear side, 3 - flexible connector on gearbox side, 4 - rigid support on gearbox side, 5 - reaction rod on differential gear side, 6 - rod fixing support on differential mechanism side) [3] 


\subsection{Measurement system}

One of the non-invasive measurement method is laser vibrometry. In this research the system was based on Laser Doppler Vibrometer (LDV). It utilizes the Doppler effect, which is the change of length of the wave in relation to an observer who is moving relatively to the source. The laser head is both transmitting and receiving device. The laser beam comes out and returns to the head after reflection from the surface. This method allows to obtain velocity and relative displacement of moving objects [2].

The measuring system consists of a Polytec PSV I 400 head, a OFV 5000 controller and a PSV W 400 supervision and acquisition device [5, 6].

During the measurements the cars were standing on their wheels. The crankshafts were rotated to the speed of 2000 min. $^{-1}$ in neutral gear. The test rig was positioned to measure the vertical-vector of the vibrations. Additional mirror was set to direct the laser beam (Fig. 2).

The authors selected two measurements points (Fig. 3, 4) on the unsprung mass to verify the difference of the detected vibrations.

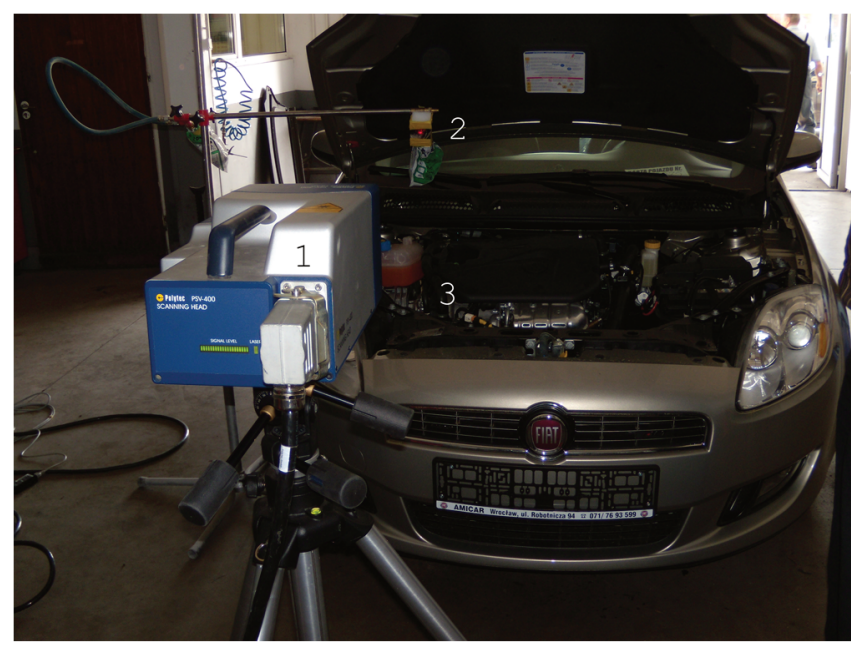

Fig. 2. Test rig (1 - laser head, 2 - mirror, 3 - measurement point on the engine mount)

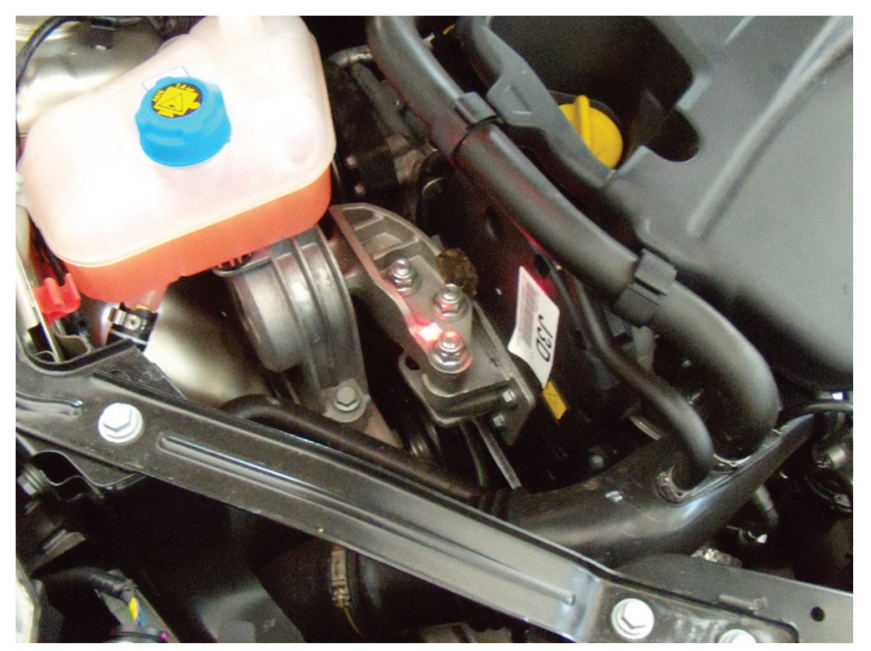

Fig. 3. Measurement point on the engine mount

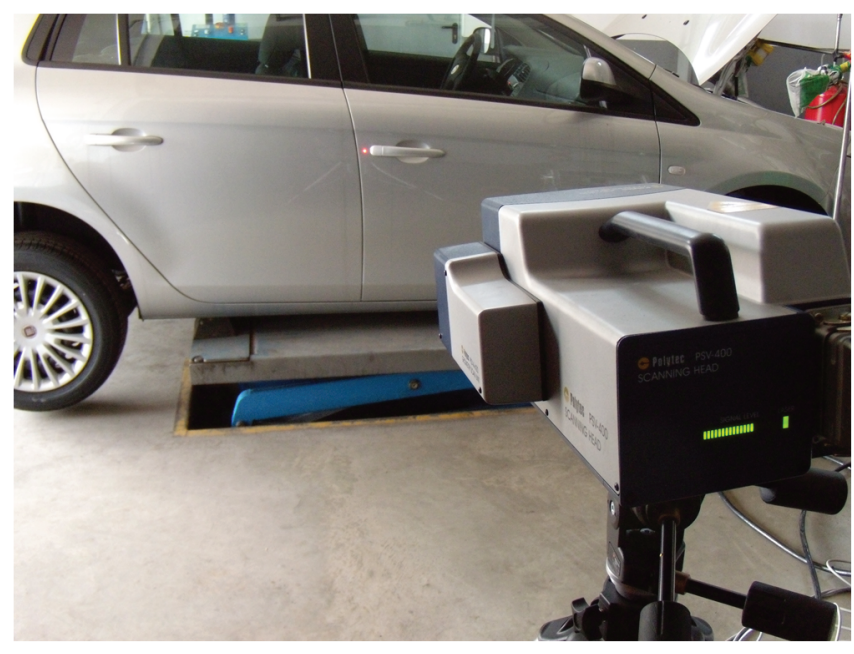

Fig. 4. Measurement point on the door handle

\section{Results}

The measurements are presented in the diagrams below. The vibrations were registered as the time courses of velocities and spectra in the frequency domain after Fast Fourier Transform [7]. The waveforms were recorded for the 2 seconds and with the $2048 \mathrm{~Hz}$ sampling frequency. This time period was chosen as adequate to recognize the characteristic of stationary/non-stationary type of signal. At the same time, with such sampling frequency, it allowed to receive large amount of measurement samples as sufficient to perform the FFT.

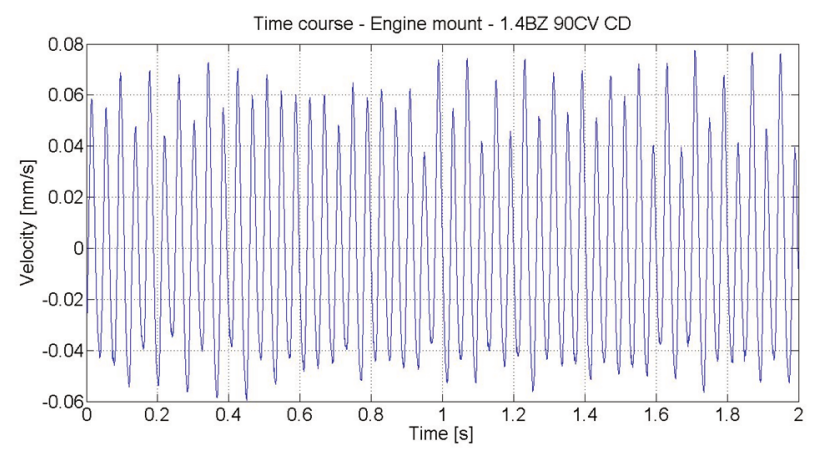

Fig. 5. Time course of the engine mount measurement point on the 1.4BZ 90CV CD engine

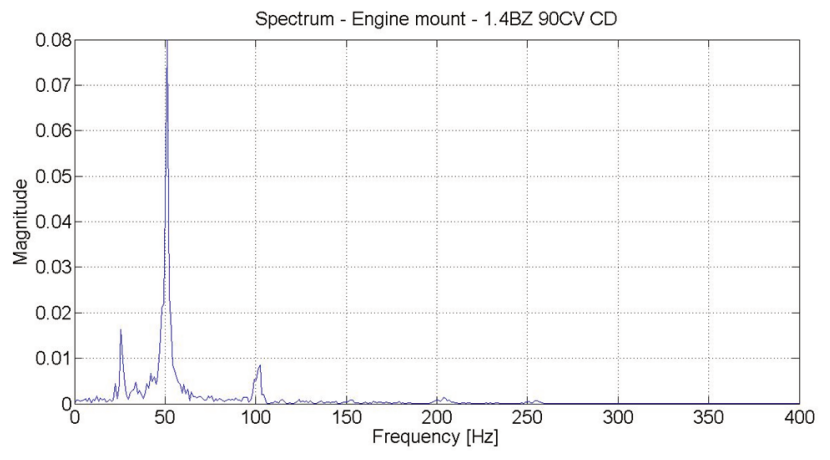

Fig. 6. Frequency spectrum of the engine mount measurement point on the 1.4BZ 90CV CD engine 


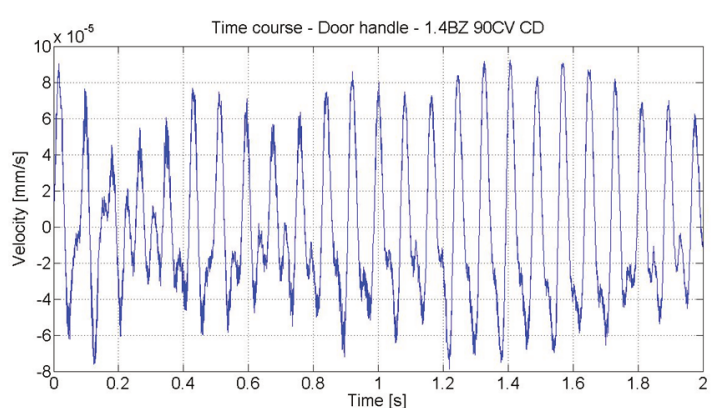

Fig. 7. Time course of the door handle point on the 1.4BZ 90CV CD

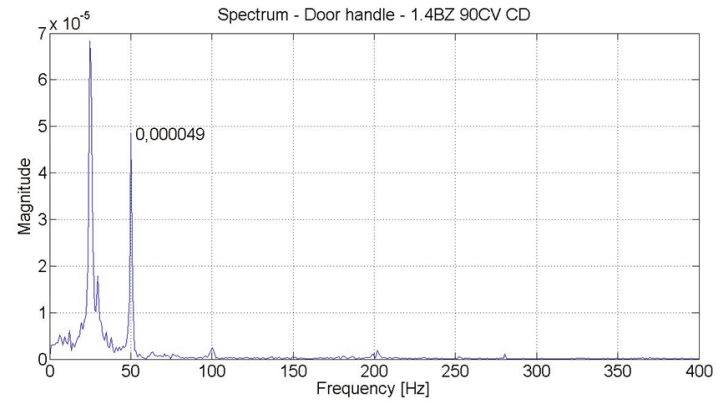

Fig. 8. Spectrum of the door handle point on the 1.4BZ 90CV CD

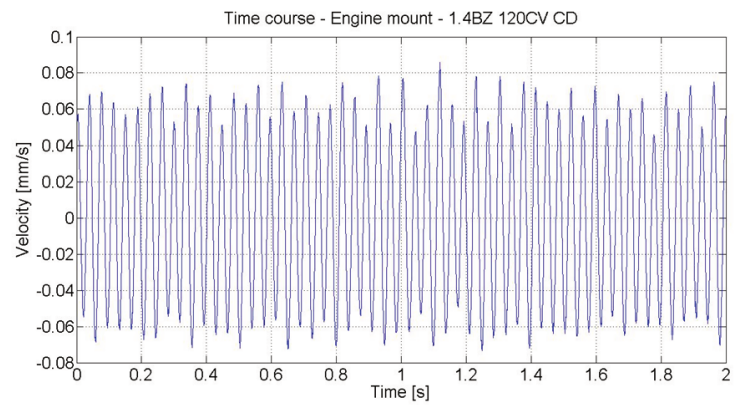

Fig. 9. Time course of the engine mount point on the 1.4BZ 120CV CD

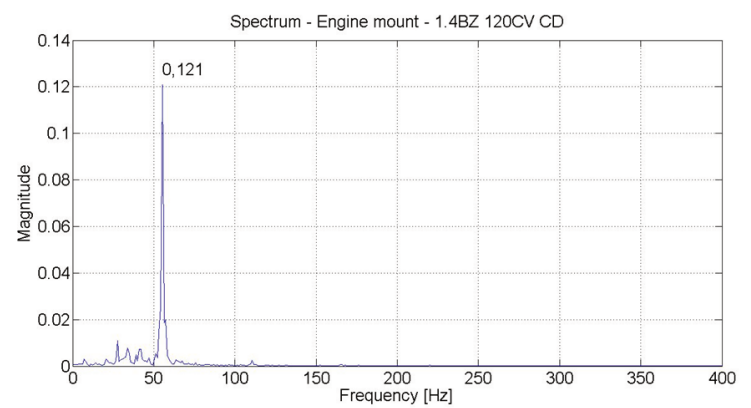

Fig. 10. Spectrum of the engine mount point on the 1.4BZ 120CV CD

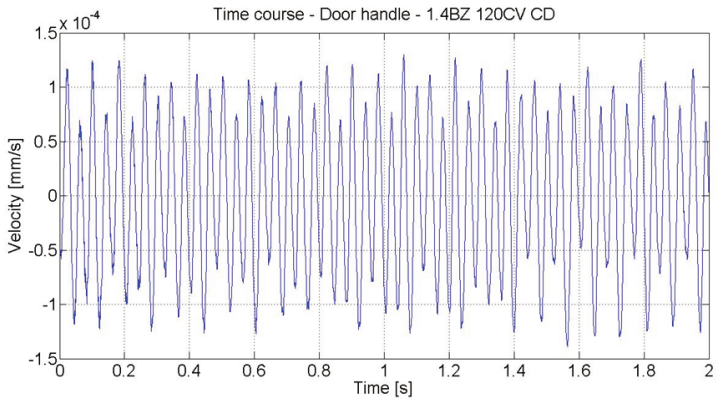

Fig. 11. Time course of the door handle point on the 1.4BZ 120CV CD

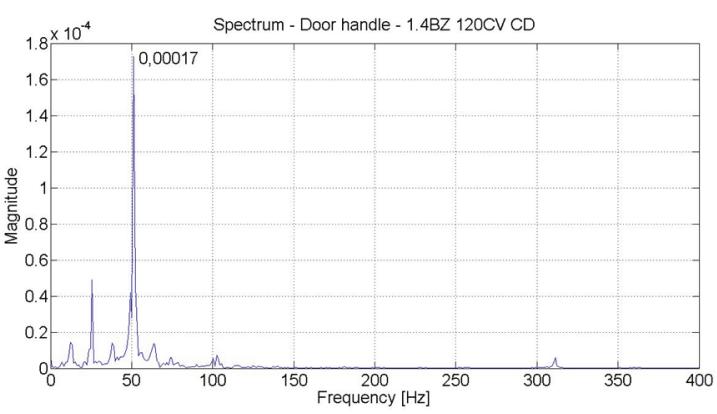

Fig. 12. Spectrum of the door handle point on the 1.4BZ 120CV CD

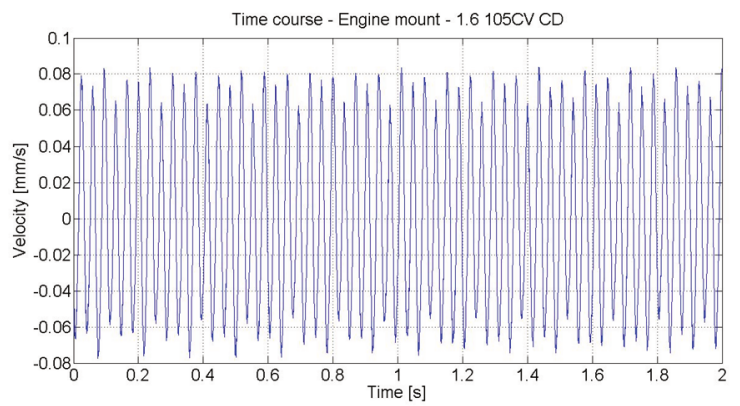

Fig. 13. Time course of the engine mount point on the $1.6105 \mathrm{CV}$ CD

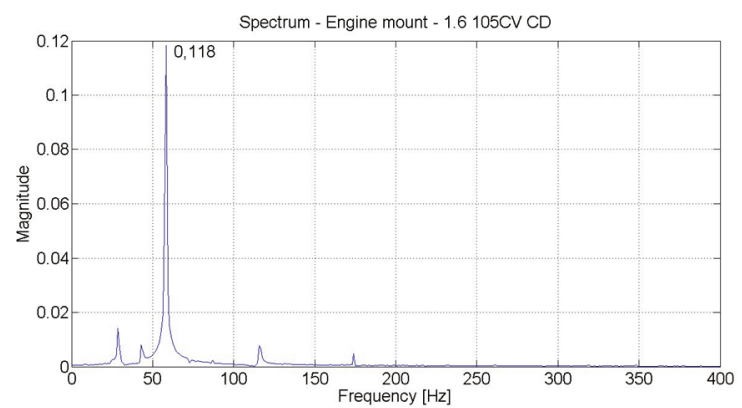

Fig. 14. Spectrum of the engine mount point on the $1.6105 \mathrm{CV}$ CD

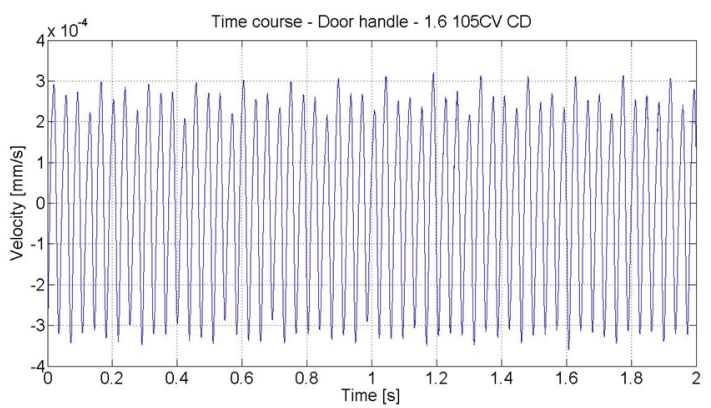

Fig. 15. Time course of the door handle point on the $1.6105 \mathrm{CV}$ CD

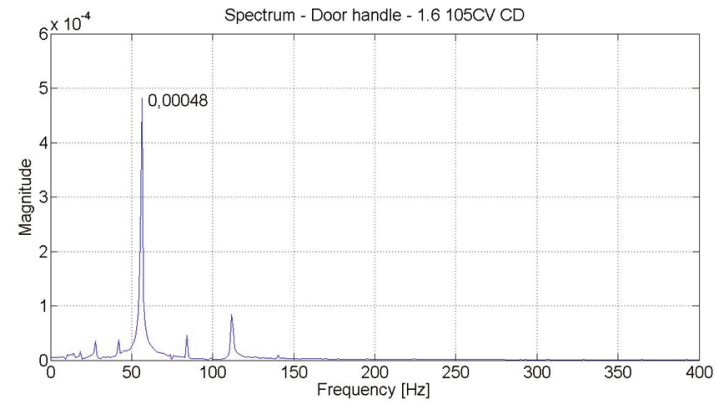

Fig. 16. Spectrum of the door handle point on the $1.6105 \mathrm{CV}$ CD 
Table 2. Vibration velocities and magnitudes

\begin{tabular}{|c|c|c|c|c|}
\hline & & $\begin{array}{c}\mathrm{V}_{\max } \\
{[\mathrm{mm} / \mathrm{s}]}\end{array}$ & $\begin{array}{c}\mathrm{V}_{\mathrm{av}} \\
{[\mathrm{mm} / \mathrm{s}]}\end{array}$ & Magnitude \\
\hline \multirow{3}{*}{ 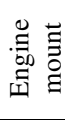 } & 1.4BZ 90CV CD & 0.077 & 0.000087 & 0.08 \\
\hline & 1.4BZ 120CV CD & 0.086 & 0.000084 & 0.121 \\
\hline & $1.6105 \mathrm{CV} C D$ & 0.084 & -0.00023 & 0.118 \\
\hline \multirow{3}{*}{ 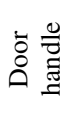 } & 1.4BZ 90CV CD & 0.000092 & -0.000000047 & 0.000049 \\
\hline & 1.4BZ 120CV CD & 0.00014 & -0.0000034 & 0.00017 \\
\hline & $1.6105 \mathrm{CV} C D$ & 0.00036 & -0.0000023 & 0.00048 \\
\hline
\end{tabular}

Based on the results, the authors were able to distinguish the damping ability of the vibrations transfer in the structure of the cars. The Fast Fourier Transform displayed the spectrum with the harmonic frequencies in every measurement run. The maximal values of those harmonics were most significant in the recorded signals. Comparing spectra after measurements in the first and second point, the authors could calculate the created for this purpose damping coefficient, which indicates what the efficiency of the damping parts was.

The coefficient was calculated as follows:

$$
\mathrm{c}=\frac{\text { magnitude value from first measured point }}{\text { magnitude value from second measured point }}
$$

Table 3. Damping coefficient

\begin{tabular}{|c|c|}
\hline Engine & $\mathrm{c}$ \\
\hline $1.4 \mathrm{BZ} 90 \mathrm{CV} \mathrm{CD}$ & 1633 \\
\hline $1.4 \mathrm{BZ} \mathrm{120CV} \mathrm{CD}$ & 712 \\
\hline $1.6105 \mathrm{CV} \mathrm{CD}$ & 246 \\
\hline
\end{tabular}

\section{Conclusions}

The vibrations as signals generated by the engine have stationary characteristic. This allows to perform Fast Fourier Transform and obtain harmonic spectrum.

The tendency of the maximum velocities increases with the engines with higher capacities and equipped with supercharger. Simultaneously, the tendency of the average velocities decreases.

In the gasoline engine, the damping phenomenon is lower in the car with more powerful engine with supercharger. The least damped vehicle structure is supercharged Diesel engine with the highest engine capacity.

The supercharger increases overall vibration level propagated in the entire structure of unsprung mass.

The damping of the mounting system is highly effective.

The spectra present that the highest frequency magnitude occur in the low range, similarly in every case and independently of the size and type of engine.

Based on the results, the authors would like to continue the research of such subject in broader range.

It would be intentional to focus on higher number of vehicle of different brands, engine sizes, body types, mileage and production year.

\section{Acknowledgements}

Research financed from Wroclaw University of Science and Technology statutory funds no. 0401/003/18.

\section{Nomenclature}
LDV laser doppler vibrometer
FFT Fast Fourier Transform
DOF degrees of freedom

$\begin{array}{ll}\text { OHC } & \text { overhead camsahft } \\ \text { DOHC } & \text { double overhead camshaft } \\ \text { HP } & \text { horse power }\end{array}$

\section{Bibliography}

[1] DE SILVA, C. Vibrations fundamentals and practice. CRC Press. NY 2000.

[2] GIERGIEL, J. Mechanical vibrations (in Polish). University Scientific-Educational Publishers. Cracow 2000.

[3] KAŹMIERCZAK, A., WRÓBEL, R. Detection of infection unit defects in diesel engine through analysis of vibrations. Journal of KONES. 2007.

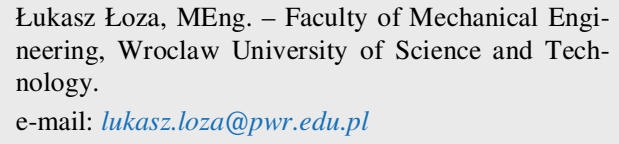
neering, Wroclaw University of Science and Technology.

e-mail: lukasz.loza@pwr.edu.pl

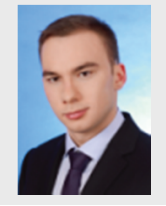

[4] FIAT Technical materials, www.fiat.com

[5] www.vibrometry.co.kr/PSV-400.pdf

[6] www.polytec.com/fileadmin/d/Vibrometrie/OM_DS_ OFV-5000_E_42346.pdf

[7] BRIGHAM, E. Fast Fourier Transform and its applications. Pearson. 1988. 